\title{
Avaliação visual e do potencial fotossintético para quantificação da ferrugem do milheto pérola e correlações com a produção
}

\author{
Antonio C.T. da Costa ${ }^{1}$, Leandro B. de Oliveira ${ }^{2}$, Margarida Goréte F. do Carmo ${ }^{2}$ \& Carlos Pimentel $^{2}$ \\ ${ }^{1}$ Centro de Ciências Agrárias, Universidade Estadual do Oeste do Paraná, 85960-000, Marechal Cândido Rondon, PR, \\ Brasil; ${ }^{2}$ Departamento de Fitotecnia, Instituto de Agronomia, Universidade Federal Rural do Rio de Janeiro, 23890-000, \\ Seropédica, RJ, Brasil
}

Autor para correspondência: Antonio C.T. da Costa, e-mail: antoniocarlos2105@yahoo.com.br

\section{RESUMO}

O presente trabalho teve como objetivo a quantificação da ferrugem, causada por Puccinia substriata var. penicillariae em milheto e avaliar suas correlações com os componentes de produção. A quantificação da ferrugem foi realizada por meio de avaliações visuais com auxílio de duas escala descritivas de notas, em cinco plantas por parcela, em três tipos amostras: planta inteira e na quinta e segunda folhas. Com os dados de severidade calcularam-se os valores de área abaixo da curva de progresso da doença (AACPD) e em seguida as correlações residuais $\left(\mathrm{r}_{\mathrm{e}}\right)$ e genéticas $\left(\mathrm{r}_{\mathrm{g}}\right)$ entre os estes valores e a produção de grãos, massa seca total e massa seca da palhada. A avaliação da severidade da ferrugem na segunda folha, a partir do estádio de florescimento do milheto, foi o método mais eficiente para quantificação da doença, pois apresentou melhores correlações com a produção de biomassa e de grãos. Um segundo experimento foi instalado em casa de vegetação para quantificação indireta da ferrugem através da medida do potencial fotossintético (Fv/Fm), por emissão de fluorescência da clorofila "a", em folhas de seis genótipos: HKP, Guerguera, Souna III, BRS 1501, ENA 1 e o composto ENA 2. Neste ensaio, ficou demonstrado que a ferrugem afetou o potencial fotossintético de folhas de milheto e a medição da fluorescência da clorofila "a", que é rápida e independe do avaliador, poderá vir a ser uma variável fisiológica para a seleção de genótipos resistentes à ferrugem.

Palavras-chave: Puccinia substriata var. penicillariae, Pennisetum glaucum, área abaixo da curva de progresso da doença, fluorescência da clorofila "a", melhoramento genético, resistência genética.

\begin{abstract}
Rust quantification by visual and photosynthetic potential evaluation and its correlations with production in families of pearl millet

The aim of the present study was to quantify rust disease caused by Puccinia substriata var. penicillariae in pearl millet and its correlations with yield components. The rust quantification was done by visual evaluations using two scales based on visual description, in five plants per plot in three different kinds of samples: entire plant and fifth and second leaves. Using these values of the area under the disease progress curve (AUDPC) the residual correlation $\left(\mathrm{r}_{\mathrm{e}}\right)$ and genetic correlations $\left(\mathrm{r}_{\mathrm{g}}\right)$ were calculated between the values of AUDPC and production of grain, total dry matter and stover dry weight. The evaluation of rust severity on the second leaf, from the flowering stage of pearl millet, was the most efficient method to quantify the disease because of the higher correlation with biomass and grain production. A second assay was conducted in a greenhouse to quantify rust disease indirectly by measuring photosynthetic potential (Fv/ Fm), by chlorophyll "a" fluorescence emission, in leaves of six genotypes: HKP, Guerguera, Souna III, BRS 1501 and ENA 1 and bulk ENA 2. In this assay, it was demonstrated that rust affected the photosynthetic potential of pearl millet leaves and that the measurement of chlorophyll "a" fluorescence, which is rapid and independent of evaluator, would be a physiological parameter for selection of rustresistant genotypes.

Keywords: Puccinia substriata var. penicillariae, Pennisetum glaucum, area under the disease progress curve, chlorophyll "a" fluorescence, genetic breeding, genetic resistance.
\end{abstract}

\section{INTRODUÇÃO}

O milheto (Pennisetum glaucum R.Br.) é semeado no Brasil em duas épocas: no final do inverno/início da

Parte da Tese de Doutorado do primeiro autor. Universidade Federal Rural do Rio de Janeiro. Seropédica RJ. 2005. primavera e após a cultura de verão, no plantio da seca denominado safrinha (Netto, 1998; Geraldo et al., 2002; Costa et al., 2005), quando há influência do fotoperíodo na produtividade, visto ser uma planta de dias curtos (Norman et al., 1995; Bidinger \& Hash, 2004). No período de cultivo da safrinha, além das condições ambientais serem desfavoráveis para a obtenção de alta 
produtividade, estas são favoráveis ao desenvolvimento da ferrugem, que é causada por Puccinia substriata var. penicillariae Ellis \& Barthol. (Carvalho et al., 2006). Esta doença é de grande importância econômica para a cultura, pois os danos causados por ela podem resultar em reduções de rendimento de até $75 \%$ da produção de grãos (Wilson et al., 1996; Pereira Filho et al., 2003). Além de causar redução na produção de biomassa do milheto, a ferrugem afeta a qualidade da forragem, reduzindo a produção de fotoassimilados (Monson et al., 1986), e diminuindo assim o valor nutricional das plantas infectadas (Wilson et al., 1994). Os sintomas da ferrugem aparecem, inicialmente, nas folhas baixeiras, em forma de pequenas manchas de coloração avermelhada. Essas manchas se desenvolvem, formando pústulas de até 3 milimetros, de aspecto ferruginoso. A região da epiderme sobre as pústulas se rompe, liberando uma massa de urediniósporos de cor avermelhada (Pereira Filho et al., 2003).

Tendo em vista a expansão da cultura e a importância dos efeitos da ferrugem no milheto, tornamse necessários estudos na área de epidemiologia e controle desta doença, ainda pouco estudada. Para isto, é fundamental dispor-se de métodos de quantificação da doença, que possam viabilizar os estudos de seu progresso, as estimativas de danos por ela causadas, as avaliações da eficiência de medidas de controle e a seleção e indicação de cultivares resistentes (Nutter et al., 2006). Existem várias técnicas, que podem ser utilizadas para avaliar a severidade de doenças, tais como: imagens de vídeo, fotografia infravermelha, emissão de fluorescência e reflectância espectral e o uso de escalas diagramáticas e descritivas, sendo esta última a mais simples e de fácil utilização (Berger, 1980; Amorim, 1995; Nilsson, 1995; Spósito et al., 2004; Nutter et al., 2006). Dentre as outras técnicas citadas, uma que é ainda pouco usada, mas que pode ser de fácil uso e rápida mensuração, com equipamento de baixo custo, é a medida da emissão de fluorescência da clorofila "a" pelas folhas, indicada para a avaliação da severidade de doenças, que podem afetar a fotossíntese das folhas (Maxwell \& Johnson, 2000; Baker, 2008), como a ferrugem.

Já a quantificação da ferrugem, utilizando escalas diagramáticas e descritivas, facilita a padronização e a mensuração visual da área foliar afetada. Embora algumas críticas tenham sido feitas com relação à rigidez dos níveis das escalas, seu uso tem sido bem sucedido, principalmente no trabalho de seleção de materiais resistentes em programas de melhoramento (Amorim, 1995). James (1971), Azevedo (1997) e Juliatti \& Santos (1999) apresentam várias escalas diagramáticas e descritivas para a quantificação de ferrugens em gramíneas como trigo, aveia e cevada, porém para a ferrugem do milheto não existe, na literatura, relato de escala ou método padronizado de quantificação. O presente trabalho teve como objetivo estabelecer metodologias, por avaliação visual, em diferentes partes da planta, e pela medida do potencial fotossintético da folha (Fv/Fm), para quantificação da ferrugem do milheto pérola e correlacionar os valores de área abaixo da curva de progresso da doença (AACPD), obtidos pelos métodos de avaliação visual, com a produção de biomassa e de grãos.

\section{MATERIAIS E MÉTODOS}

Um experimento de campo foi instalado em março de 2003 para as avaliações visuais da severidade da ferrugem, em um planossolo, na área do Campo Experimental da Fitotecnia - Horticultura, da Universidade Federal Rural do Rio de Janeiro, município de Seropédica RJ, situada entre os paralelos $22^{\circ} 45^{\prime}$ e $22^{\circ} 49^{\prime}$ de latitude Sul e os meridianos $43^{\circ} 38^{\prime}$ e $43^{\circ} 42^{\prime}$ de longitude Oeste, e entre 35 a $40 \mathrm{~m}$ de altitude. O clima da região é do tipo Aw, da classificação de Köpen, com verão quente e chuvoso e inverno seco. $\mathrm{O}$ delineamento experimental utilizado foi um látice triplo $12 \times 12$, totalizando 144 tratamentos (progênies) com três repetições. Cada parcela foi constituída por dez plantas, em uma linha de cinco metros, com espaçamento de 0,5 $\mathrm{m}$ entre linhas e $0,5 \mathrm{~m}$ entre plantas, resultando em uma população de 40.000 plantas ha $^{-1}$. A umidade relativa do ar (média) ocorrida durante a condução do experimento foi de $67,7 \%$ e as temperaturas máxima, mínima e média foram de $28,8^{\circ} \mathrm{C}, 18,7^{\circ} \mathrm{C}$ e $23^{\circ} \mathrm{C}$, respectivamente.

A quantificação da ferrugem, em campo, foi realizada por meio de avaliações visuais com auxílio de escala descritiva, em cinco plantas por parcela, totalizando 15 plantas avaliadas por progênie. Quantificou-se a severidade de três diferentes formas: i. na segunda folha, marcada de cima para baixo (principal fonte da panícula, a partir da floração, pois a folha bandeira é muito pequena); ii. na quinta folha, também marcada de cima para baixo (folha completamente expandida no início da avaliação) e iii. na planta inteira. Nas avaliações realizadas na segunda e na quinta folhas tomou-se como base a escala diagramática descrita por Peterson et al. (1948), considerando-se as seguintes classes: $0=$ ausência de sintomas; $1=0,1$ a $3 \% ; 2=3$ a $7 \% ; 3=7$ a $13 \% ; 4=13$ a $25 \% ; 5=26$ a $55 \% ; 6=56$ a $80 \%$ e $7>$ $80 \%$ de área foliar lesionada. Nas avaliações realizadas na planta inteira, utilizou-se escala descrita por Chester (1950), onde: $0=0$ até $1 \% ; 1=1$ a $10 \% ; 2=10$ a $25 \%$; $3=25$ a $60 \% ; 4=60$ a $80 \%$ e $5>80 \%$ de área foliar lesionada.

As avaliações na quinta folha e na planta inteira foram realizadas a partir do $17^{\circ}$ dia após a emergência das plantas (DAE), prosseguindo a cada sete dias até o $67^{\circ}$ DAE, totalizando oito avaliações. As da segunda folha foram realizadas a partir do estádio de florescimento (53 DAE), prosseguindo a cada sete dias até atingir a maturação fisiológica (80 DAE), totalizando cinco 
avaliações. Todo o processo foi executado sempre pelo mesmo avaliador. Ao final do ciclo da cultura, aos 85 DAE, foi feita a colheita das plantas e avaliação de massa seca total e da palhada e da produção de grãos.

Com os valores de severidade da ferrugem, estimados com auxílio das escalas de Peterson et al. (1948) e Chester (1950), construíram-se as curvas de progresso da doença e calcularam-se os valores de área abaixo da curva de progresso (AACPD) conforme (Shanner \& Finney, 1977), considerando-se diferentes períodos de avaliação. Nas avaliações realizadas na quinta folha e na planta inteira, calcularam-se, ainda, os valores de AACPD para dois intervalos de tempo: i. considerandose todas as observações desde a primeira avaliação, aos $17 \mathrm{DAE}$, até $45 \mathrm{DAE}$ e, ii. considerando-se todas as observações desde a primeira avaliação aos 17 DAE até 67 DAE; com o intuito de se determinar o melhor período para quantificação da doença no campo. Nas avaliações realizadas na segunda folha, que surge somente a partir o florescimento e atua como folha bandeira e fonte para a panícula, pois a primeira folha é muito pequena e com baixo conteúdo de N (Pimentel et al., 2003), calcularamse os valores de AACPD considerando-se desde a sua primeira avaliação, por ocasião do florescimento aos 53 DAE, até atingir o estádio de maturação fisiológica, aos 80 DAE. Com os dados de progresso da ferrugem gerados pelos três métodos de quantificação, contruíram-se curvas representativas tendo como base os dados extremos, com maior e menor AACPD, e o ponto mediano.

Com os diferentes valores de AACPD obtidos calcularam-se o quadrado médio de progênies $\left(\mathrm{QM}_{\text {pros }}\right)$, quadrado médio do erro $\left(\mathrm{QM}_{\text {erro }}\right)$, coeficiente de variaçã̃o do erro experimental (CV\%), coeficiente de variação genética $\left(\mathrm{CV}_{\mathrm{G}} \%\right)$, coeficiente de variação fenotípica $\left(\mathrm{CV}_{\mathrm{F}} \%\right)$ e a herdabilidade ao nível de médias $\left(\mathrm{h}^{2}{ }_{\mathrm{m}}\right)$ para as 144 progênies. As expressões utilizadas para os cálculos de $\mathrm{h}_{\mathrm{m}}^{2}$ (herdabilidade ao nível de médias), $\mathrm{S}$ $\left(\mathrm{h}_{\mathrm{m}}^{2}\right)$ (erro padrão da herdabilidade), $\mathrm{CV}_{\mathrm{G}}$ (coeficiente de variação genética), $\mathrm{CV}_{\mathrm{F}}$ (coeficiente de variação fenotípica), correlações genéticas $\left(\mathrm{r}_{\mathrm{g}}\right)$ e residuais $\left(r_{e}\right)$ foram obtidas em Vencovsky \& Barriga (1992). Calcularam-se, ainda, o Quadrado Médio de progênies $\left(\mathrm{QM}_{\text {prog }}\right)$, o Quadrado Médio do erro $\left(\mathrm{QM}_{\text {erro }}\right)$, e o $\mathrm{CV} \%$, para as 144 progênies, considerando-se apenas os dados pontuais da severidade aos 30 e aos 45 dias após a emergência, avaliada na quinta folha e na planta inteira. Em seguida, calcularam-se as correlações residuais $\left(\mathrm{r}_{\mathrm{e}}\right)$ e genéticas $\left(\mathrm{r}_{\mathrm{g}}\right)$ entre os diferentes valores de AACPD e a produção de grãos, massa seca total e massa seca da palhada. Finalmente, calcularam-se as correlações residuais $\left(r_{e}\right)$ e genéticas $\left(r_{g}\right)$ entre os diferentes valores da AACPD, calculados a partir da avaliação da ferrugem na segunda folha (a partir do florescimento), na quinta folha (avaliação feita até os 45 DAE; avaliação feita até o final do ciclo), e na planta inteira (avaliação feita até os 45 DAE; avaliação feita até o final do ciclo), e avaliação pontual (severidade da ferrugem) aos 30 e 45 DAE na quinta folha e na planta inteira.

Um segundo experimento foi instalado em setembro de 2004, em casa de vegetação no Departamento de Fitotecnia, da Universidade Federal Rural do Rio de Janeiro, município de Seropédica RJ, para quantificação da ferrugem através da medida do potencial fotossintético da folha inoculada. O solo utilizado foi um Planassolo retirado na profundidade de $20 \mathrm{~cm}$, cuja análise química revelou: $\mathrm{pH}$ em água 5,$4 ; \mathrm{Ca}, 4,0 \mathrm{cmol}_{\mathrm{c}} / \mathrm{dm}^{3} ; \mathrm{P}, 55 \mathrm{mg} /$ $\mathrm{dm}^{3} ; \mathrm{Mg}, 1,6 \mathrm{cmol}_{\mathrm{c}} / \mathrm{dm}^{3} ; \mathrm{K}, 59 \mathrm{mg} / \mathrm{dm}^{3} \mathrm{e} \mathrm{Al}^{+3} 0,0 \mathrm{cmol}_{\mathrm{c}} /$ $\mathrm{dm}^{3}$. A semeadura foi feita em vasos colocando-se cinco sementes por vaso, onde foi realizado um desbaste sete dias após, deixando-se duas plantas por vaso. Durante o experimento, as temperaturas médias da máxima e da mínima e umidade relativa, respectivamente, foram: $37,8^{\circ} \mathrm{C} ; 19,7^{\circ} \mathrm{C}$ e $66 \%$.

$\mathrm{O}$ delineamento experimental utilizado foi $\mathrm{o}$ inteiramente casualizado, em um esquema fatorial $6 \times 2 \times 2$, totalizando 24 tratamentos, com quatro repetições. Foram utilizados seis genótipos de milheto pérola, sendo três africanos (cultivares HKP, Guerguera e Souna III) e três brasileiros (cultivares BRS 1501 e ENA 1 e o composto ENA 2), inoculados ou não com os urediniósporos, com avaliação em duas regiões da folha, no terço médio e no terço superior. A inoculação foi realizada aos 22 dias após a semeadura, por meio de atomização nas faces dorsal e ventral das folhas, até o ponto de escorrimento, com uma suspensão de urediniospóros, contendo $4 \times 10^{5}$ esporos. $\mathrm{mL}^{-1}$ ajustados em hemacitômetro, em água com uma gota de Tween 80. Os ueridiniósporos foram coletados, com auxílio de um pincel, em plantas infectadas no campo.

As avaliações fisiológicas, do potencial fotossintético $(\mathrm{Fv} / \mathrm{Fm})$, foram realizadas aos 18 dias após a inoculação, pela medida da emissão de fluorescência da clorofila "a", obtida com um fluorímetro (OS-30 da ADC Ltd. Inglaterra), segundo proposto por Maxwell \& Johnson (2000) e Baker (2008). Estas avaliações foram realizadas na quarta folha (basal), onde foram feitas quatro leituras ao acaso para cada parte da folha, no terço superior ou mediano desta, em cada uma das quatro repetições do experimento, pois são medidas rápidas, em menos de um minuto, o que permite um grande número de avaliações (Maxwell \& Johnson, 2000). Os dados de potencial fotossintético foram submetidos à análise de variância e as médias comparadas pelo teste de StudentNews-Kewls, a 5,0\% de probabilidade.

\section{RESULTADOS E DISCUSSÃO}

No experimento de campo, os primeiros sintomas da ferrugem foram observados aos 17 DAE quando se iniciaram as quantificações na quinta folha e na planta inteira, prosseguindo-se até os $67 \mathrm{DAE}$, quando se iniciou a senescência dessa folha e da planta; já as avaliações 
na segunda folha, emitida no florescimento, foram realizadas a partir dos $53 \mathrm{DAE}$ até os $80 \mathrm{DAE}$, enquanto não se observava senescência desta folha (Figuras $1 \mathrm{a}, \mathrm{b}$, c). As avaliações foram realizadas também na segunda folha, pois esta tem maior área foliar e conteúdo em $\mathrm{N}$ que a primeira folha próxima da panícula, podendo ser considerada a sua principal fonte de carbono (Geraldo et al., 2002; Pimentel et al., 2003). Nas avaliações efetuadas na planta inteira, observou-se progresso contínuo da doença até os 67 DAE para a maioria das progênies, enquanto na quinta folha, os valores máximos de severidade foram observados a partir de 50 DAE, provavelmente devido à senescência desta folha (Figura 1b). Nesta fase do ciclo, todas as progênies apresentavam valores de severidade superior a $50 \%$, na quinta folha, enquanto na segunda folha estes valores variavam de 10 a $50 \%$. Os valores máximos de severidade na segunda folha, no entanto, foram atingidos por volta de $60 \mathrm{DAE}$ nas progênies mais suscetíveis enquanto naquelas mais resistentes somente a partir de 72 DAE (Figura 1a).

Quanto a resistência à ferrugem, observaramse diferenças significativas entre as progênies de milheto $(\mathrm{p}<1 \%)$, determinada pelos valores da AACPD, calculados a partir das avaliações de severidade feitas na segunda e quinta folhas e na planta inteira (Tabela 1). Em experimentos com progênies de meios-irmãos, o valor do quociente entre $\mathrm{CV}_{\mathrm{G}}$ e $\mathrm{CV}$ próximo ou igual a 1,0 indicou que a variável pode ser útil para a seleção de plantas (Vencovsky \& Barriga, 1992). Assim, o valor de 0,89 encontrado para o quociente entre o $\mathrm{CV}_{\mathrm{G}}$ e o $\mathrm{CV}$ para a avaliação da ferrugem na segunda folha indica que este é um bom método para se quantificar a ferrugem do milheto. Além disso, a AACPD, calculada a partir da avaliação da severidade da ferrugem na segunda folha, apresentou o maior valor de $\mathrm{h}^{2}(0,70)$ (Tabela 1$)$, o que mostra que o caráter tem herdabilidade para a próxima geração. Já as avaliações da severidade da ferrugem, na quinta folha ou na planta inteira, feitas aos 30 e aos 45 DAE, não se mostraram adequadas para a quantificação da doença, pois apresentaram altos coeficientes de variação e não revelaram diferenças entre as progênies testadas (Tabela 2).

As análises das correlações, residuais e genéticas, entre os valores de AACPD, calculados com os três critérios de avaliação nos diferentes períodos, e os caracteres de importância agronômica, como a produção de grãos e de massa seca total e da palhada, mostram diferenças entre as três formas de avaliação visual, sendo destacadas positivamente as avaliações na quinta folha e, sobretudo, na segunda folha (Tabela 3), que é a principal folha fonte para a panícula (Pimentel et al., 2003). Registraram-se correlações genéticas negativas, altamente significativas, entre os valores de AACPD, obtidos a partir da severidade da ferrugem na segunda folha e na quinta folha, tanto na avaliação até os $45 \mathrm{DAE}$ como até o final do ciclo da cultura, com as variáveis de produção de grãos e massa seca total e da palhada; sendo que os valores mais expressivos foram obtidos nas avaliações na segunda folha. Ainda na Tabela 3, para
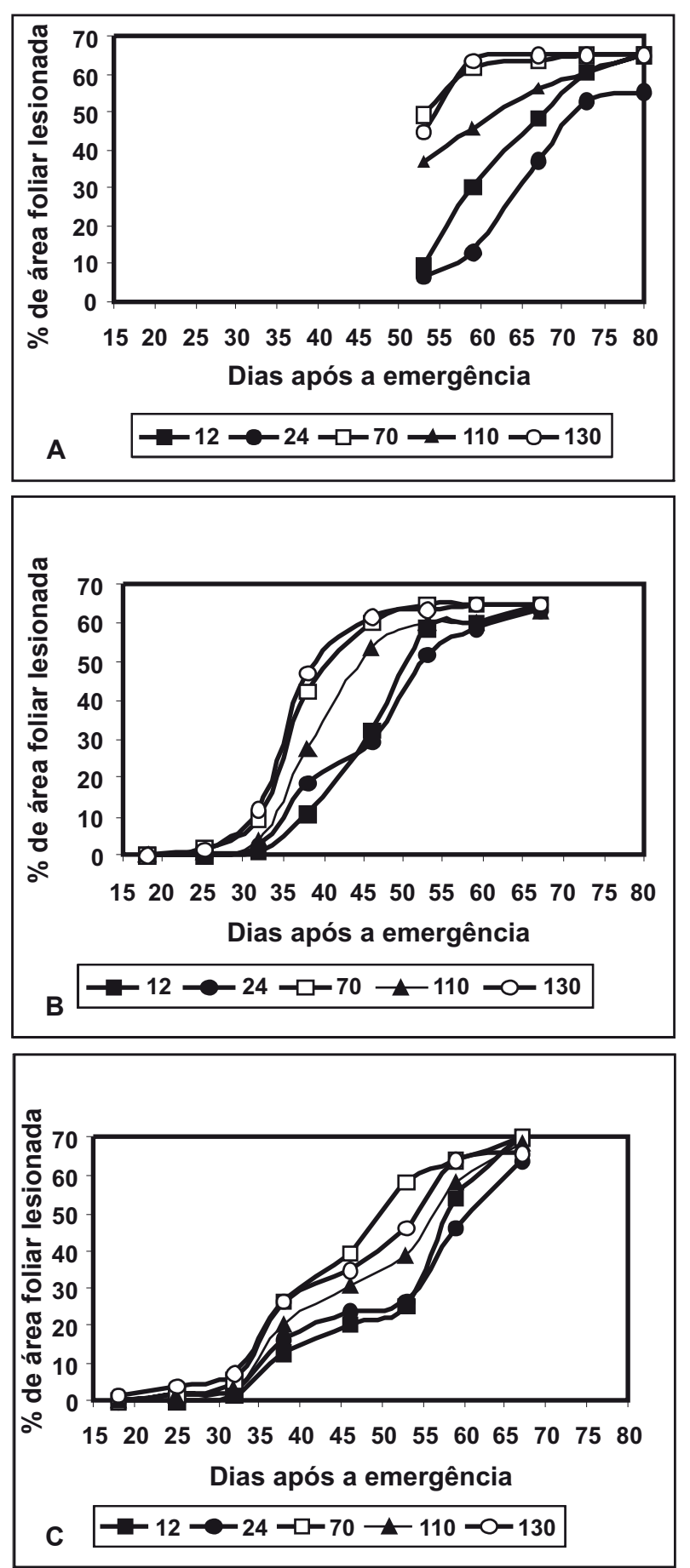

FIGURA 1 - Curva de progresso da ferrugem do milheto em cinco genótipos de milheto pérola (dois com os maiores valores de AACPD [70 e 130], dois com os menores valores de AACPD [12 e 24] e um com valor de AACPD mediano [110]), sob condições de infecção natural no campo, construídas com base na quantificação avaliada na A. segunda folha; B. na quinta folha; C. e na planta inteira. 
TABELA 1 - Quadrado médio de progênies $\left(\mathrm{QM}_{\text {prog }}\right)$, quadrado médio do erro $\left(\mathrm{QM}_{\text {erro }}\right)$, coeficiente de variação do erro experimental $(\mathrm{CV} \%)$, coeficiente de variação genética $\left(\mathrm{CV}_{\mathrm{G}} \%\right)$, coeficiente de variação fenotípica $\left(\mathrm{CV}_{\mathrm{F}} \%\right)$, herdabilidade ao nível de médias $\left(\mathrm{h}^{2}{ }_{\mathrm{m}}\right)$, em 144 progênies de milheto de meios irmãos, para os valores da AACPD calculados a partir da severidade da ferrugem na segunda folha (a partir do florescimento), na quinta folha (avaliação feita até os $45 \mathrm{DAE}$; avaliação feita até o final do ciclo) e na planta inteira (avaliação feita até os 45 DAE; avaliação feita até o final do ciclo)

\begin{tabular}{llcccc}
\hline \hline Parâmetro & $\begin{array}{c}\text { ACCPD na } \\
\text { segunda folha }\end{array}$ & $\begin{array}{c}\text { ACCPD na quinta } \\
\text { folha (até o final do } \\
\text { ciclo) }\end{array}$ & $\begin{array}{c}\text { ACCPD na quinta } \\
\text { folha (até os 45 } \\
\text { DAE) }\end{array}$ & $\begin{array}{c}\text { ACCPD na planta } \\
\text { inteira (até o final do } \\
\text { ciclo) }\end{array}$ & $\begin{array}{c}\text { ACCPD na planta } \\
\text { inteira (até os 45 } \\
\text { DAE) }\end{array}$ \\
\hline $\mathrm{QM}_{\text {prog }}$ & $39681,33^{* *}$ & $37900,29 * *$ & $15819,70^{* *}$ & $23381,26^{* *}$ & $4749,47^{* *}$ \\
$\mathrm{QM}_{\mathrm{erro}}$ & 11788,26 & 16154,36 & 8130,96 & 16379,27 & 3863,28 \\
$\mathrm{CV} \%$ & 11,00 & 7,48 & 21,2 & 9,47 & 18,83 \\
$\mathrm{CV}$ & 9,77 & 5,01 & 11,90 & 3,58 & 5,21 \\
$\mathrm{CV}_{\mathrm{F}} \%$ & 14,71 & 9,00 & 24,31 & 10,12 & 19,53 \\
$\mathrm{~h}^{2} \mathrm{~m}+2 \mathrm{~S}\left(\mathrm{~h}^{2} \mathrm{~m}\right)$ & $0,70 \pm 0,095$ & $0,57 \pm 0,137$ & $0,49 \pm 0,165$ & $0,30 \pm 0,225$ & $0,19 \pm 0,261$ \\
\hline
\end{tabular}

**Significativo ao nível de $1 \%$ pelo teste $\mathrm{F}$.

TABELA 2 - Quadrado Médio de progênies $\left(\mathrm{QM}_{\text {prog }}\right)$, Quadrado Médio do erro $\left(\mathrm{QM}_{\text {erro }}\right)$ e Coeficiente de Variação (CV\%), em 144 progênies de milheto de meios irmãos, para a severidade da ferrugem avaliada na quinta folha e na planta inteira, aos 30 e 45 dias após a emergência (DAE)

\begin{tabular}{ccccc}
\hline \hline & $\begin{array}{c}\text { Avaliação feita aos 30 DAE } \\
\text { na quinta folha }\end{array}$ & $\begin{array}{c}\text { Avaliação feita aos 45 DAE } \\
\text { na quinta folha }\end{array}$ & $\begin{array}{c}\text { Avaliação feita aos 30 DAE } \\
\text { na planta inteira }\end{array}$ & $\begin{array}{c}\text { Avaliação feita aos 45 DAE } \\
\text { na planta inteira }\end{array}$ \\
\hline $\mathrm{QM}_{\text {prog }}$ & $13,68^{\mathrm{ns}}$ & $937,51^{\mathrm{ns}}$ & $6,95^{\mathrm{ns}}$ & $28,71^{\mathrm{ns}}$ \\
$\mathrm{QM}$ & 1064,59 & 7,03 & 29,52 \\
$\mathrm{CV} \%$ & 11,63 & 65,55 & 52,47 & 18,69 \\
\hline
\end{tabular}

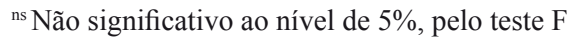

TABELA 3 - Correlações residuais $\left(\mathrm{r}_{\mathrm{e}}\right.$ ) e genéticas $\left(\mathrm{r}_{\mathrm{o}}\right.$ ) entre os valores da AACPD, calculado a partir de avaliação da ferrugem na segunda folha (a partir do florescimento), na quinta folha (avaliação feita até os 45 DAE; avaliação feita até o final do ciclo), e na planta inteira (avaliação feita até os 45 DAE; avaliação feita até o final do ciclo), com a produção de grãos, massa seca total e massa seca da palhada, em 144 progênies de meios-irmãos de milheto, semeadas em março de 2003

\begin{tabular}{|c|c|c|c|c|c|c|}
\hline & & $\begin{array}{l}\text { ACCPD na } \\
\text { segunda folha }\end{array}$ & $\begin{array}{c}\text { ACCPD na quinta } \\
\text { folha (até o final do } \\
\text { ciclo) }\end{array}$ & $\begin{array}{c}\text { ACCPD na quinta } \\
\text { folha (até os } 45 \\
\text { DAE) }\end{array}$ & $\begin{array}{c}\text { ACCPD na planta } \\
\text { inteira (até o final do } \\
\text { ciclo) }\end{array}$ & $\begin{array}{c}\text { ACCPD na planta } \\
\text { inteira (até os } 45 \\
\text { DAE) }\end{array}$ \\
\hline \multirow{2}{*}{$\begin{array}{l}\text { Produção } \\
\text { de grãos }\end{array}$} & $\mathrm{r}_{\mathrm{e}}$ & $0,182 * *$ & $0,110^{\mathrm{ns}}$ & $0,089^{\mathrm{ns}}$ & $0,208 * *$ & $0,224 * *$ \\
\hline & $r_{g}$ & $0,585^{* *}$ & $-0,415^{* *}$ & $-0,313 * *$ & $-0,210^{*}$ & $-0,096^{\mathrm{ns}}$ \\
\hline \multirow{2}{*}{$\begin{array}{l}\text { Massa } \\
\text { Seca total }\end{array}$} & $r_{e}$ & $0,234 * *$ & $0,139^{*}$ & $0,116^{\mathrm{ns}}$ & $0,256^{* *}$ & $0,248 * *$ \\
\hline & $\mathrm{rg}_{\mathrm{g}}$ & $0,538 * \underset{*}{ }$ & $-0,417 * *$ & $-0,320 * *$ & $-0,035^{\mathrm{ns}}$ & $0,154^{\mathrm{ns}}$ \\
\hline \multirow{2}{*}{$\begin{array}{l}\text { Massa } \\
\text { seca da } \\
\text { palhada }\end{array}$} & $r_{e}$ & $0,216^{* *}$ & $0,105^{\mathrm{ns}}$ & $0,079^{\mathrm{ns}}$ & $0,226 * *$ & $0,209 * *$ \\
\hline & $\mathrm{r}_{\mathrm{g}}$ & $0,496^{* *}$ & $-0,394 * *$ & $-0,307 * *$ & $-0,027^{\mathrm{ns}}$ & $-0,256^{*}$ \\
\hline
\end{tabular}

$\mathrm{r}_{\mathrm{g}}$ : correlação genética. * ** Significativo ao nível de 5 e $1 \%$, respectivamente, pelo teste t (segundo Vencovsky \& Barriga, 1992). $\mathrm{r}_{\mathrm{e}}$ : correlação residual. Valores críticos $\mathrm{r}_{(253,1 \%)}=0,160$ e $\mathrm{r}_{(253,5 \%)}=0,122$ (Steel \& Torrie, 1960).

as avaliações realizadas na planta inteira, observou-se correlação genética significativa, e negativa, apenas entre os valores de AACPD, calculados com os dados de severidade até o final do ciclo, e a produção de grãos e entre os valores de AACPD, calculados com os dados de severidade até os 45 DAE, e a massa seca da palhada (Tabela 3 ). 
Estas correlações $\left(r_{\mathrm{g}}\right)$ significativas e negativas, apresentadas na Tabela 3, mostram que os genótipos com maior resistência à ferrugem do milheto também tiveram alta produção de biomassa e de grãos, neste experimento. Na presença do patógeno, a produção de carboidratos da folha pode ser reduzida, uma vez que a ferrugem diminui a área foliar fotossinteticamente ativa das folhas (Monson et al., 1986), o que pode afetar a produtividade, mesmo nos genótipos mais resistentes.

Por outro lado, a resistência quantitativa, mesmo sendo controlada geneticamente, pode ser influenciada por fatores ambientais, tais como: nutrição, temperatura, comprimento do dia, intensidade luminosa e umidade (Fry, 1982; Zambolim \& Ventura, 1993). Assim, as correlações residuais (ambientais), que são independentes dos efeitos de progênie e de repetição, entre os valores de AACPD, obtidos na segunda folha e na planta inteira, e os caracteres agronômicos, como massa seca total e produção de grãos, foram positivas e significativas (Tabela 3), enquanto que o mesmo não ocorreu para os valores de AACPD calculados a partir da avaliação da severidade na quinta folha. Ao contrário das correlações genéticas $\left(\mathrm{r}_{\mathrm{g}}\right)$, que foram negativas, as correlações residuais $\left(\mathrm{r}_{\mathrm{e}}\right)$ foram positivas e mostram que algumas parcelas mais produtivas também podem ter maior severidade da ferrugem, provavelmente devido a um efeito favorável do ambiente, em algumas parcelas, sobre o desenvolvimento da planta e, consequentemente, o da doença. Isto pode ser atribuído ao fato de $P$. substriata var. penicillariae ser um patógeno biotrófico, que apenas infecta e coloniza tecido vivo (Kubiak, 2003). Assim, a presença e manutenção de tecido bem nutrido, por maior período de tempo, provavelmente favorece o desenvolvimento do patógeno. Desta forma, é provável que fatores ambientais favoráveis à maior produção de fotoassimilados (carboidratos), em algumas parcelas (maior umidade e fertilidade do solo, por exemplo), possam ter contribuído também para um maior desenvolvimento do patógeno e, assim, para uma maior severidade da doença em plantas mais produtivas, mesmo sendo afetadas pela ferrugem.

Ao se efetuarem as análises de correlações entre os diferentes valores de AACPD, obtidos com os três critérios nos diferentes períodos de avaliação, e as avaliações pontuais de severidade aos 30 e 45 DAE, observaram-se, em geral, coeficientes significativos e positivos, tanto nas residuais quanto nas genéticas (Tabela 4). Somente a avaliação pontual da severidade da ferrugem, feita na quinta folha aos $45 \mathrm{DAE}$, teve menos correlações significativas com os demais caracteres avaliados, provavelmente devido ao fato dos níveis de severidade da ferrugem já terem atingido o valor máximo, nesta avaliação aos $45 \mathrm{DAE}$, em muitos dos genótipos testados, não permitindo a discriminação dos mesmos (Figura 1b).

As diferenças obtidas entre os métodos de quantificação, provavelmente, se devem à dinâmica da doença, ao comportamento fisiológico da planta e à precisão do método. Na avaliação feita na segunda folha, que é considerada uma folha fisiologicamente ativa durante toda a fase de enchimento do grão, segundo Norman et al. (1995), com o surgimento de pústulas jovens, houve uma melhor discriminação entre as progênies; enquanto a quinta folha, a partir dos 45 dias, já se encontrava em processo de senescência ou com os níveis máximos de severidade, dificultando assim a avaliação e a discriminação das progênies, a partir desta época. Na planta inteira, por sua vez, apesar dos níveis médios de severidade terem sido mais baixos que os da quinta folha, havia o predomínio de folhas mais velhas e senescentes sobre as folhas mais jovens ou fisiologicamente ativas distorcendo as estimativas da severidade.

Tendo em vista os resultados obtidos, a avaliação da severidade da ferrugem na segunda folha, a partir do estádio de florescimento do milheto, foi o método mais eficiente para proceder à quantificação desta doença, visto que esta avaliação apresentou melhor correlação com a produção de biomassa e de grãos (Tabela 3). Além disto, este método apresentou o maior valor de herdabilidade e também o maior valor do quociente entre o $\mathrm{CV}_{\mathrm{G}}$ e o $\mathrm{CV}$ (Tabela 1). Na escolha do método para quantificar uma doença, alguns fatores devem ser considerados, como tempo e praticidade, e dentre os métodos testados neste primeiro experimento, a quantificação da ferrugem na segunda folha foi o que melhor atendeu a estes quesitos, mas demanda maior tempo de cultivo do milheto. Nos casos em que houver a necessidade de se quantificar a ferrugem mais cedo, antes do florescimento do milheto até os 45 DAE, a avaliação na quinta folha poderá ser adotada, pois este método também apresentou correlação genética negativa e significativa com a produção de biomassa e de grãos (Tabela 3 ).

No segundo experimento em casa de vegetação, foram feitas avaliações do potencial fotossintético (Fv/ Fm) das plantas de milheto que, ao contrário da avaliação visual, independem da percepção do avaliador (Maxwell \& Johnson, 2000), e observaram-se diferenças significativas entre o tratamento inoculado e não inoculado (testemunha) e entre dois dos seis genótipos estudados [Fator A e C, na Tabela 5]. Para o tratamento de inoculação, foram observados menores valores de potencial fotossintético (Fv/Fm) nas plantas infectadas, provavelmente devido ao efeito do processo de colonização da folha na fotossíntese das plantas, e à presença de áreas lesionadas pela ferrugem (Tabela 5). Estes resultados confirmam a afirmação de Monson et al.,(1986), de que a ferrugem do milheto causa redução tanto da produção de biomassa quanto da qualidade da forragem, devido à redução da produção de fotoassimilados nas plantas infectadas. Não houve, porém, diferença significativa quanto ao potencial fotossintético em relação à posição ou parte da folha avaliada (terço mediano e terço superior) [Fator B, da Tabela 5]. 
Avaliação visual e do potencial fotossintético para quantificação da ferrugem...

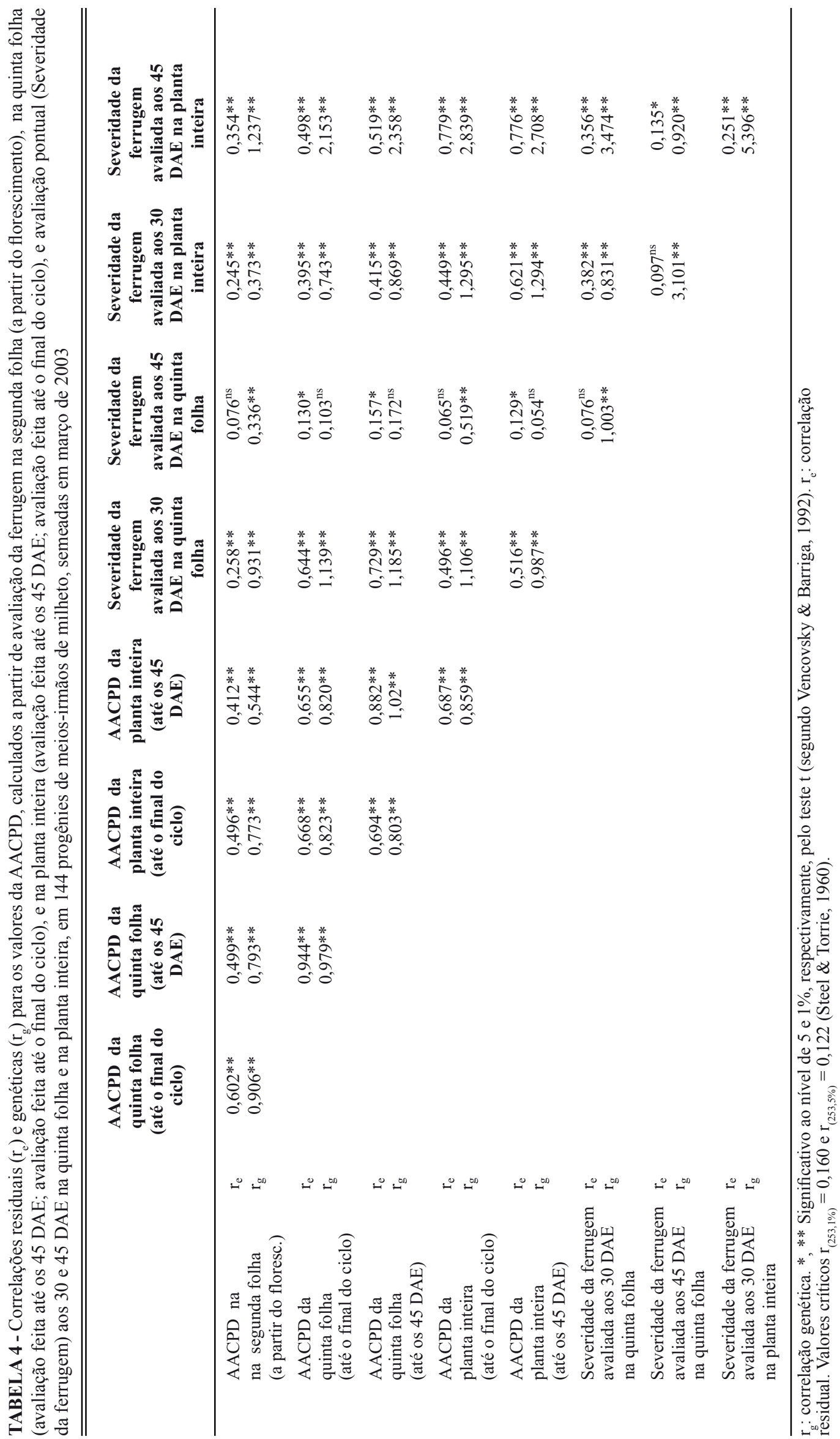


TABELA 5 - Médias da avaliação da ferrugem, realizadas por fluorescência da clorofila (medida do potencial fotossintético [Fv/Fm]), com um fluorímetro, aos 18 dias após a inoculação, em plantas cultivadas em casa de vegetação

\begin{tabular}{|c|c|c|}
\hline Fatores & Tratamentos & $\mathbf{F v} / \mathbf{F m}$ \\
\hline $\begin{array}{l}\text { Fator A }{ }^{1} \\
\text { (inoculação) }\end{array}$ & $\begin{array}{l}\text { Sem inoculação } \\
\text { Com inoculação }\end{array}$ & $\begin{array}{l}0,812 \mathrm{a} \\
0,787 \mathrm{~b}\end{array}$ \\
\hline $\begin{array}{l}\text { Fator } B^{1} \\
\text { (parte da folha) }\end{array}$ & $\begin{array}{l}\text { Terço médio } \\
\text { Terço superior }\end{array}$ & $\begin{array}{l}0,802 \mathrm{a} \\
0,797 \mathrm{a}\end{array}$ \\
\hline $\begin{array}{l}\text { Fator } C^{2} \\
\text { (cultivares) }\end{array}$ & $\begin{array}{l}\text { HKP } \\
\text { ENA 1 } \\
\text { Guerguera } \\
\text { Souna III } \\
\text { BRS 1501 } \\
\text { Composto ENA 2 }\end{array}$ & $\begin{array}{l}0,801 \mathrm{ab} \\
0,792 \mathrm{ab} \\
0,803 \mathrm{ab} \\
0,806 \mathrm{ab} \\
0,783 \mathrm{~b} \\
0,812 \mathrm{a}\end{array}$ \\
\hline
\end{tabular}

${ }^{1}$ Médias seguidas da mesma letra, na coluna, não diferem entre si, ao nível de $5 \%$ pelo teste $\mathrm{F}$.

${ }^{2}$ Médias seguidas da mesma letra, na coluna, não diferem entre si, ao nível de 5\% pelo teste de Student-News-Kewls.

Além de diferenciar o efeito da inoculação, a avaliação do potencial fotossintético, também permitiu detectar diferenças significativas entre dois dos genótipos estudados [Fator C, da Tabela 5], mas não para a interação cultivares versus inoculação. A cultivar BRS 1501 diferiu estatisticamente do composto ENA 2, com menores valores de potencial fotossintético nas folhas da cultivar BRS 1501 que nas folhas do Composto ENA 2, que por sua vez não diferiu estatisticamente das cultivares HKP, ENA 1, Guerguera e Souna III [Fator C, da Tabela 5]. Este resultado pode explicar aqueles relatados por Costa et al (2007) para maior resistência quantitativa de plantas do Composto ENA 2 à ferrugem, expressa pelo menor progresso da doença, maior período latente médio, menor freqüência de infecção e menor tamanho das lesões, em relação a todos os demais genótipos testados, incluindo o BRS 1501. Esta maior resistência deve-se ao fato de o Composto ENA 2 ter sido selecionado no período da seca, conseqüentemente na presença da doença.

Contudo, a medição do potencial fotossintético, apesar de evidenciar o efeito da inoculação e entre os genótipos, como sugerido por Maxwell \& Johnson (2000) e Baker (2008), não permitiu determinar diferenças nas interações duplas inoculação x cultivar e posição da folha x cultivar, e na interação tripla, mas, de uma maneira geral, observou-se uma tendência para valores mais baixos de potencial fotossintético das cultivares inoculadas, sugerindo a necessidade de mais ensaios, com maior número de medições e repetições, para a indicação do uso desta variável $(\mathrm{Fv} / \mathrm{Fm})$, de rápida mensuração (menos de um minuto), como forma de quantificação da ferrugem, independente da percepção do avaliador.
Assim sendo, com base nos resultados obtidos, pode-se afirmar que a escala de notas baseada na escala diagramática de Peterson et al. (1948), para quantificação da ferrugem em cereais, pode ser utilizada para a ferrugem do milheto. As avaliações devem ser feitas na segunda folha, a partir do estádio de florescimento da planta, quando surge esta folha, pois este foi o método mais eficiente para proceder à quantificação da ferrugem do milheto, visto que, além de ser mais prático, apresentou maior correlação com a produção de biomassa e de grãos, maior valor de herdabilidade, maior valor do quociente entre o $\mathrm{CV}_{\mathrm{G}}$ e o CV. Contudo, para obtenção de resultados mais rápidos, antes do florescimento, a quantificação na quinta folha também poderá ser utilizada, com a coleta de dados até os 45 DAE, pois este método também apresentou correlação genética significativa com a produção de biomassa e de grãos.

Além disto, as correlações genéticas mostram que os genes que conferem resistência à ferrugem no milheto ocorrem em genótipos com alta produção de biomassa e de grãos, o que foi confirmado com as medidas de potencial fotossintético $(\mathrm{Fv} / \mathrm{Fm})$, pois as plantas de milheto inoculadas com o patógeno apresentam menores valores deste potencial. A avaliação da emissão de fluorescência da clorofila "a", o potencial fotossintético, precisa ser mais bem estudado, pois pode vir a ser uma variável fisiológica útil, independente da percepção do avaliador, em trabalhos futuros para a seleção de genótipos resistentes à ferrugem.

\section{REFERÊNCIAS BIBLIOGRÁFICAS}

Amorim L (1995) Avaliação de doenças. In: Bergamin Filho A, Kimati H, Amorim L (Eds.) Manual de Fitopatologia, 3ed. São Paulo SP. Agronômica Ceres.

Azevedo LAS (1997) Manual de quantificação de doenças de plantas. São Paulo SP.

Baker NR (2008) Chlorophyll Fluorescence: A probe of photosynthesis in vivo. Annual Review of Plant Biology 59:89113.

Berger RD (1980) Measuring disease intensity. In: Teng PS, Krupa SV (Eds.) Crop loss assessment. St. Paul MN. University of Minnesota. pp. 28-31.

Bidinger FR, Hash CT (2004) Pearl Millet. In: Nguyen HT, Blum A (Eds.) Physiology and biotechnology integration for plant breeding. New York NY. Marcel Dekker. pp. 238-284.

Carvalho AO, Soares DJ, Costa ACT, Carmo MGF, Pimentel C (2006) Description of the life-cycle of the pearl millet rust fungusPuccinia substriata var. penicillariae with a proposal of reducing var. indica to a synonym. Mycopathologia 161:331-336.

Chester KS (1950) Plant disease losses: their appraisal and interpretation. Plant Disease Reporter Supplement 193:191-362. 
Costa ACT, Geraldo J, Pereira MB, Pimentel C (2005) Unidades térmicas e produtividade em genótipos de milheto semeados em duas épocas. Pesquisa Agropecuária Brasileira 40:1171-1177.

Costa ACT, Carvalho AO, Soares DJ, Carmo MGF, Pimentel C (2007) Condições de ambiente favoráveis à germinação e à infecção de Puccinia substriata var. penicillariae em diferentes cultivares de milheto pérola. Fitopatologia Brasileira 32:400-407.

Fry WE (1982) Epidemiology: dynamics of interacting pathogen and host populations. In: Fry, W.E. (Ed.). Principles of plant disease management. New York NY. Academic Press. pp. 43-65.

Geraldo J, Oliveira LD, Pereira MB, Pimentel C (2002) Fenologia e produção de massa seca e de grãos em cultivares de milheto pérola. Pesquisa Agropecuária Brasileira 37:1263-1268.

James WC (1971) An illustrated series of assessment keys for plant diseases, their preparation and usage. Canadian Plant Disease Survive 51:39-65.

Juliatti CF, Santos MA (1999). Métodos de avaliação de doenças de plantas induzidas por fungos e nematóides. Revisão Anual de Patologia de Plantas 7:407-455.

Kubiak DM (2003) Influência da palhada de milheto na ocorrência de ramulose (Colletotrichum gossypii var. cephalosporioides Costa) no algodoeiro. Dissertação de Mestrado. ESALQ, Universidade de São Paulo. Piracicaba SP.

Maxwell K, Johnson, GN (2000) Chlorophyll fluorescence: a practical guide. Journal of Experimental Botany 51:659-668.

Monson WG, Hanna WW, Gaines TP (1986) Effects of rust on yield and quality of pearl millet forage. Crop Science 36:637639.

Netto DAM (1998) A cultura do milheto. Comunicado Técnico, no. 11. Sete Lagoas MG. Embrapa Milho e Sorgo.

Nilsson HE (1995) Remote sensing and image analysis in plant pathology. Canadian Journal of Plant Pathology 17:154-166.

Norman MJT, Pearson CJ, Searle PGE (1995) Pearl millet (Pennisetum glaucum). In: Norman MJT, Pearson CJ, Searle PGE
(Eds.). The ecology of tropical food crops. Cambridge. Cambridge University Press. pp 64-181.

Nutter Jr. FW, Esker PD, Netto RAC (2006) Disease assessment concepts and the advancements made in improving the accuracy and precision of plant disease data. European Journal of Plant Pathology 115:95-103.

Pereira Filho IAP, Ferreira AS, Coelho AM, Casela CR, Karam D, Rodrigues JAS, Cruz JC, Waquil JM (2003) Manejo da cultura do milheto. Circular Técnica, no. 29. Sete Lagoas MG. Embrapa Milho e Sorgo.

Peterson RF, Campbell AB, Hannah AE (1948) A diagrammatic scale for estimating rust intensity of leaves and stem of cereals. Canadian Journal of Research Section C 26:496-500.

Pimentel C, Geraldo J, Costa ACT, Preira MB, Magalhães, JR (2003) Traits of nitrogen use efficiency for selection of Pennisetum glaucum in na environment of nutrient limitations. Physiology and Molecular Biology of Plants 9:111-116.

Shaner G, Finney RE (1977) The effect of nitrogen fertilization on the expression of slow mildewing resistance in knox wheat. Phytopathology 67:1051-1056.

Spósito MB, Amorim L, Belasque Junior J, Bassanezi RB, Quino R (2004) Elaboração e validação de escala diagramática para avaliação da severidade da mancha preta em frutos cítricos. Fitopatologia Brasileira 29:81-85.

Vencovsky R, Barriga P (1992) Genética Biométrica no Fitomelhoramento. Ribeirão Preto SP. Sociedade Brasileira de Genética.

Wilson JP, Hanna WW, Gascho GJ (1996) Pearl millet grain yield loss from rust infection. Journal of Production Agriculture 9:543-545.

Wilson JP, Hanna WW, Gates RN (1994) Stability of forage and quality in pearl millet hybrids heterogeneous for rust resistance. Euphytica 72:163-170.

Zambolim L, Ventura JA (1993) Resistência induzida pela nutrição mineral das plantas. Revisão Anual de Patologia de Plantas 1:275318. 